\title{
Changes in Dynamic Pelvic Floor Magnet Resonance Imaging and Patient Satisfaction after Resection Rectopexy for Obstructed Defecation Syndrome
}

\section{Auswirkungen der Resektionsrektopexie auf den Beckenboden und die Lebensqualität von Patienten mit ODS (obstructed defecation syndrome)}

Authors

Affiliations
M. Reichert ${ }^{1}$, A. Busse ${ }^{1}$, A. Hecker ${ }^{1}$, I. Askevold ${ }^{1}$, M. Kampschulte ${ }^{2}$, O. Wüsten ${ }^{2}$, G. A. Krombach² ${ }^{2}$ T. Schwandner ${ }^{1}$, W. Padberg ${ }^{1}$

Department of General and Thoracic Surgery, University Hospital of Giessen, Germany

Department of Diagnostic and Interventional Radiology, University Hospital of Giessen, Germany
Key words

abdomen

anus

rectum

- defecography

- laparoscopy

- MR-functional imaging

received 2.6.2015

accepted 26.7.2015

Bibliography

DoI http://dx.doi.org/

10.1055/s-0041-105406

Published online: 1.9.2015

Fortschr Röntgenstr 2016; 188:

38-44 (c) Georg Thieme Verlag

KG Stuttgart · New York .

ISSN 1438-9029

\section{Correspondence}

Martin Reichert

Department of General and Thoracic Surgery, University Hospital of Giessen

Rudolf Buchheim Street 7

35392 Giessen

Germany

Tel.: ++ 49/641/98544701

Fax: $++49 / 641 / 98544709$

martin.reichert@chiru.med.uni-

giessen.de

\section{Zusammenfassung}

$\nabla$

Ziel: Die Resektionsrektopexie (RR) kann mit guten funktionellen postoperativen Ergebnissen und niedrigen Rezidivraten bei Patienten mit ODS (obstructed defecation syndrome) durch einen Rektumprolaps oder Sigmoidozele eingesetzt werden. Dabei ist jedoch wenig über die postoperativen dynamischen Veränderungen des Beckenbodens bekannt.

Material und Methoden: Innerhalb von drei Jahren wurden 26 Patientinnen prospektiv in die Studie eingeschlossen. Indikationen zur RR (22 laparoskopisch, 3 primär offen und 1 konvertiert) waren der Rektumprolaps III $^{\circ}$ bei 11 und die Sigmoidozele bei 15 Patientinnen. Lebensqualität (QOL), Stuhlgewohnheiten und defäkations-assoziierte Schmerzen wurden vor und nach der chirurgischen Therapie erfasst durch Anamnese, klinische Untersuchung, Rand 36-idem health survey (SF-36), Cleveland-Clinic Incontinence Score (CCIS) und visuelle Analogskala für defäkations-assoziierte Schmerzen (VAS). Veränderungen in der Beckenbodenanatomie und -funktion wurden mittels dynamischen Beckenboden-MRT (dPF-MRI) vor und nach RR erfasst.

Ergebnisse: Die RR verbessert den Grad der Stuhlinkontinenz $(p<0,01)$ und den CCIS $(p=0,01)$. Der Laxanzienabusus $(p=0,01)$, die Notwendigkeit der manuellen Stuhlausräumung $(p=0,02)$ und die VAS $(p<0,01)$ waren postoperativ reduziert, was in einer Verbesserung der QOL (overall $\mathrm{p}<0,01)$ resultierte. MRT-morphologisch zeigte sich postoperativ eine Verkürzung der $\mathrm{H}-$, jedoch nicht der M-Linie in Ruheposition $(p<0,01)$ und während des Defäkationsprozesses $(p=0,04)$. Bei allen Patienten wurde im präoperativen dPFMRI eine Rektozele diagnostiziert, die sich postoperativ signifikant kleiner darstellte $(p<0,01)$. Durch die Veränderungen kam es postoperativ zu einer Verbesserung der Rate an kompletter Stuhlentleerung im dPF-MRI $(p<0,01)$. Im Fol-

\section{Abstract \\ $\nabla$}

Purpose: Resection rectopexy (RR) provides good functional results and low recurrence rates for the treatment of obstructed defecation syndrome based on rectal prolapse and cul-de-sac syndrome, whereas little is known about changes in pelvic floor dynamics and patient satisfaction after surgery.

Materials and Methods: Within three years 26 consecutive female patients were prospectively included. Indications for RR (22 laparoscopic, 3 primary open and 1 converted-to-open) were rectal prolapse III $^{\circ}$ in 11 patients and cul-de-sac syndrome in 15 patients. Patients' quality of life (QOL), fecal behavior and defecation-associated pain were investigated before and after surgical treatment using anamnesis and clinical examination, Rand 36-idem health survey (SF-36), Cleveland-Clinic Incontinence Score (CCIS) and the visual analog scale for defecation-associated pain (VAS). Dynamic pelvic floor magnet resonance imaging (dPF-MRI) was used for the investigation of changes in pelvic floor anatomy and function before and after surgery.

Results: RR improved the rate of fecal incontinence $(p<0.01)$ and CCIS $(p=0.01)$. The use of laxatives $(p=0.01)$, the need for self-digitation $(p=0.02)$ and VAS $(p<0.01)$ were decreased, leading to improvements in QOL (overall $\mathrm{p}<0.01$ ). RR led to shortening of the $\mathrm{H}$-line but not of the M-line under rest $(p<0.01)$ and during defecation $(p=0.04)$. A rectocele was co-incident in all patients in dPF-MRI before surgery. RR led to a reduction $(p<0.01)$ and declined protrusion $(p=0.03)$ of the rectocele. This results in a decreased rate of culde-sac $(p<0.01)$ and increased rate of complete defecation $(p<0.01)$ after surgery. At the $36-$ month follow-up no recurrence was observed.

Conclusion: RR promises high rates of patient satisfaction and improvement in pelvic floor anatomy in select patients. 
low-up von 36 Monaten konnten keine Rezidive beobachtet werden.

Schlussfolgerung: Die RR führt zu Verbesserungen der QOL und Beckenbodenanatomie sowie -funktion in ausgewählten Patienten mit ODS.

Kernaussagen:

- Die RR verbessert die Beckenbodenanatomie von Patienten mit ODS

- Die RR verbessert die Lebensqualität von Patienten mit ODS

- Verbesserungen in der Beckenbodenanatomie führen zu einer höheren QOL

- Die RR ist eine geeignete Therapieoption für ausgewählte Patienten mit ODS
Key Points:

- RR improves the pelvic floor anatomy of patients suffering from ODS

- RR improves the QOL of patients suffering from ODS

- An improvement in pelvic floor anatomy led to an improved QOL

- RR is an adequate treatment for select patients suffering from ODS

Citation Format:

- Reichert M, Busse A, Hecker A et al. Changes in Dynamic Pelvic Floor Magnet Resonance Imaging and Patient Satisfaction after Resection Rectopexy for Obstructed Defecation Syndrome. Fortschr Röntgenstr 2016; 188: 38-44

\section{Introduction}

$\nabla$

A large meta-analysis reported a pooled prevalence of chronic constipation of $14 \%$, with an increase by age [1]. Within the group of patients with chronic constipation, obstructed defecation syndrome (ODS) is prevalent in approximately $50 \%$ of cases $[1,2]$. ODS is the clinical manifestation of an insufficient posterior compartment of the pelvic floor (PF) and must be discriminated from slow-transit and other forms of chronic constipation. Insufficiency of the posterior compartment of the PF frequently results in rectal prolapse, cul-de-sac syndrome, intussusception and rectocele. One main symptom of patients diagnosed with ODS is constipation [3].

Conservative treatment for chronic constipation includes biofeedback mechanisms, stool regulation and intensification of physical activity [4]. Rectal prolapse, cul-de-sac, rectocele and intussusception as the causes of severe ODS can be treated surgically after failed conservative treatment by perineal and transabdominal approaches [5].

Within transabdominal approaches, the isolated fixation of the rectum (rectopexy) and combined fixation of the rectum with resection of the elongated part of the colon (resection rectopexy, RR) are established and reliable for the treatment of ODS caused by rectal prolapse and cul-de-sac syndrome [5-7]. Rectopexy alone has a low recurrence rate and improves anal incontinence [8]. However, some studies revealed that after isolated rectopexy alone the recurrence and incidence of postoperative constipation are increased compared with RR for the treatment of rectal prolapse [911]. The current literature describes low mortality and recurrence rates for RR and good functional results especially for the abandonment of any external material in the pexy part of the surgical approach $[5,12]$.

Although dynamic PF-magnet resonance imaging (dPF-MRI) is an established diagnostic tool for the underlying diseases of ODS, there is no evidence about changes in PF anatomy after RR [13]. In this study we prospectively evaluated changes in PF anatomy and dynamics by dPF-MRI and correlated them with clinical outcome and patient satisfaction after RR.

\section{Materials and Methods \\ $\nabla$}

\section{Patients and study design}

Within three years 26 consecutive female patients ( $58 \pm 24$ years) met the inclusion criteria ( $\bullet$ Table 1 ) and were recruited prospectively at our university hospital. After conservative treatment had failed, patients were referred to RR for the treatment of ODS caused by rectal prolapse III $^{\circ}$ and/or cul-de-sac syndrome. Rectal prolapse III $^{\circ}$ was defined as a complete circular prolapse of the rectal mucosa with the necessity of manual reposition. Cul-de-sac syndrome was defined as a PF descensus leading to an enterocele. The study was approved by the local ethics committee and informed consent was obtained from each patient. Each patient was treated by the local standard of care.

To evaluate differences in PF anatomy and function, dPF-MRI was performed before surgery ( $n=23$ patients) and thereafter ( $n=25$ patients). In order to investigate fecal behavior and continence, clinical outcome and QOL, clinical examination and anamnesis were performed in all patients and all patients responded to the Cleveland Clinic Incontinence Score (CCIS) [14], the visual analog scale for defecation-associated pain (VAS) and the Rand 36-item health survey (SF-36) pre- and postoperatively.

Relevant parameters of patient characteristics and indications for RR are described in $\bullet$ Table 2 . The follow-up time was 36 months.

\section{Dynamic pelvic floor magnet resonance imaging}

The colon and rectum were cleansed by clyster. $200 \mathrm{ml}$ of a transanally applied ultrasonic gel was used as the detection medium. Patients were in a supine position with slightly spread legs. dPF-MRI was performed at rest, under abdominal pressure and during the defecation process in coronal, axial and sagittal sections in T2 weighted turbo-spin echo sequences and in sagittal cine-sequences (dynamic balanced fast field echo: Dyn-bFFE sequence) adjusted to the rectum and anal canal. Changes in PF anatomy and dynamics were objectified by measurement of the $\mathrm{H}$-line for hiatal widening and M-line for hiatal descent as previously described ( $\bullet$ Fig.3) $[15,16]$. Further details were described by Schwandner et al. [17].

\section{Operation technique}

All patients received bowel cleansing and a single-shot antibiotic prior to surgery. Patients were placed in lithotomy position, and

Table 1 Inclusion and exclusion criteria.

Tab. 1 Einschluss- und Ausschlusskriterien.

\begin{tabular}{|c|c|}
\hline inclusion criteria & exclusion criteria \\
\hline $\begin{array}{l}\text { age }>18 \text { years } \\
\text { failure of conservative treatment } \\
\text { outlet obstruction caused by } \\
\text { - rectal prolapse } \text { III }^{\circ} \\
\text { - cul-de-sac syndrome } \\
\text { - combined disease with recto- } \\
\text { cele and/or intussusception }\end{array}$ & $\begin{array}{l}\text { age }<18 \text { years } \\
\text { isolated rectocele } \\
\text { slow-transit obstipation } \\
\text { malignancy of the colon } \\
\text { and rectum }\end{array}$ \\
\hline
\end{tabular}


for laparoscopic RR the optical trocar was positioned supraumbilically. After abdominal exploration three additional laparoscopic accesses were placed. After mobilization of the colon sigmoideum and rectum by total mesorectal excision down to the PF, resection was performed through a mini-laparotomy in the left lower abdomen. Continuity of the colon was restored using a $33 \mathrm{~mm}$ intraluminal circular stapler. For rectopexy the anterior wall of the rectum, distal to the anastomosis, was fixed to the peritoneum by Lahodny suture, thus the rectum was lifted adequately out of the PF. Previous abdominal surgery was no contraindication for the laparoscopic approach in general.

The open RR was performed with analogous operation steps using a lower median laparotomy.

\section{Statistical analysis}

Data were expressed as mean \pm SEM. Statistical analyses were performed using IBM SPSS version 11.5. Wilcox signed-rank test was performed as a nonparametric test to compare the results before and after treatment. p-values $<0.05$ indicate statistical significance.

\section{Results}

The indications for RR after failure of conservative treatment were rectal prolapse $\mathrm{III}^{\circ}$ in 11 patients and cul-de-sac syndrome in 15 patients. dPF-MRI showed that cul-de-sac was coincidental in 18 patients, enterocele in 12, intussusception in 5 and cystocele in 16 patients. Indicated by the length of the M-line in dPF-MRI, descensus of the PF was observed in all (23) patients before surgery. Complete defecation was detected in dPF-MRI preoperatively in only 2 cases ( $\bullet$ Table 2, $\bullet$ Fig. 2). It is noteworthy that the patients consulted a specialized institution for colorectal diseases $5.7 \pm 10.9$ years after the onset of the first symptoms. In 22 patients RR was completed laparoscopically, in 1 patient the laparoscopic procedure was converted to open surgery due to severe adhesions and 3 patients were primarily treated by conventional open surgery. 12 patients had undergone prior hysterectomy. The patients had $2.2 \pm 1.2$ deliveries whereby 14 patients complained of obstetric trauma in the perineal region ( $\bullet$ Table 2 ).

No intraoperative complication was observed. Postoperatively one patient suffered from a transanal hemorrhage, originating from the anastomosis, which was sufficiently treated by endoscopic clipping and blood transfusion. Minor complications were observed in 6 patients ( $\bullet$ Table 2 ).

\section{Changes in defecation behavior}

Fecal incontinence was graded according to three degrees: the disability to retain flatus $\left(\mathrm{I}^{\circ}\right)$, liquid $\left(\mathrm{II}^{\circ}\right)$ or formed stool $\left(\mathrm{III}^{\circ}\right)$. Fecal continence was significantly improved after the surgical treatment. Before the operation only 7 of the patients were continent for stool versus 13 thereafter $(p<0.01,0$ Table 3$)$.

Fewer patients complained of hard defecation (chronic constipation), while more patients described soft and formed defecation after surgery, resulting in a reduced use of laxatives $(p=0.01)$ as well as a reduced need of self-digitation $(p=0.02)$ after treatment (० Table 3).

Significant differences were investigated in CCIS (from $10.0 \pm 1.3$ before to $7.3 \pm 1.0$ after surgery, $\mathrm{p}=0.01$ ) and defecation was less painful after treatment, indicated by a decrease in VAS $(\mathrm{p}<0.01$, - Table 3).
Table 2 Patient characteristics and perioperative results.

Tab. 2 Patientencharakteristika und perioperative Ergebnisse.

\begin{tabular}{|c|c|c|c|}
\hline \multirow[t]{2}{*}{$\operatorname{sex}$} & male & 0 & $0 \%$ \\
\hline & female & 26 & $100 \%$ \\
\hline age [years] & $58 \pm 24$ & & \\
\hline weight [kg] & $69 \pm 12$ & & \\
\hline size $[\mathrm{cm}]$ & $164 \pm 6$ & & \\
\hline diabetes [n] & 5 & & $19 \%$ \\
\hline familiar deposition [n] & 8 & & $31 \%$ \\
\hline deliveries [n] & $2.2 \pm 1.2$ & & \\
\hline obstetric pelvic trauma [n] & 14 & & $54 \%$ \\
\hline hysterectomy [n] & 12 & & $46 \%$ \\
\hline $\begin{array}{l}\text { consultation of a specialist } \\
\text { after first symptoms [a] }\end{array}$ & $5.7 \pm 10.9$ & & \\
\hline \multirow[t]{2}{*}{ clinical indication } & rectal prolapse III $^{\circ}$ & 11 & $42 \%$ \\
\hline & $\begin{array}{l}\text { cul-de-sac and com- } \\
\text { bined disease with } \\
\text { intussusception } \\
\text { and/or rectocele }\end{array}$ & 15 & $58 \%$ \\
\hline \multirow[t]{6}{*}{ preoperative MRI diagnosis } & complete defecation & 2 & $8 \%$ \\
\hline & pelvic floor descensus & 23 & $100 \%$ \\
\hline & cul-de-sac & 18 & $78 \%$ \\
\hline & cystocele & 16 & $70 \%$ \\
\hline & enterocele & 12 & $52 \%$ \\
\hline & intussusception & 5 & $22 \%$ \\
\hline \multirow[t]{3}{*}{ operation technique } & laparoscopic surgery & 22 & $85 \%$ \\
\hline & converted-to-open & 1 & $4 \%$ \\
\hline & primary open surgery & 3 & $12 \%$ \\
\hline operation time [h] & $2.8 \pm 0.6$ & & \\
\hline ICU [d] & $0.5 \pm 0.5$ & & \\
\hline $\begin{array}{l}\text { postoperative hospitali- } \\
\text { zation [d] }\end{array}$ & $8 \pm 2$ & & \\
\hline \multirow[t]{2}{*}{ major complications [n] } & $\begin{array}{l}\text { bleeding from the } \\
\text { anastomosis with } \\
\text { severe anemia, endo- } \\
\text { scopic clipping and } \\
\text { blood transfusion }\end{array}$ & 1 & $4 \%$ \\
\hline & $\begin{array}{l}\text { anastomosis insuffi- } \\
\text { ciency }\end{array}$ & 0 & $0 \%$ \\
\hline minor complications [n] & 6 & & $23 \%$ \\
\hline $\begin{array}{l}\text { in-hospital and 30-day } \\
\text { mortality }\end{array}$ & 0 & & $0 \%$ \\
\hline
\end{tabular}

\section{Changes in pelvic floor anatomy and function}

The $\mathrm{H}$-line was significantly shortened at rest $(\mathrm{p}<0.01)$ as well as under abdominal pressure $(p=0.04)$, indicating a reduced hiatal widening of the levator ani muscle after surgical treatment. No differences were found in the length of the M-line after surgery, meaning that RR had no significant impact on PF descensus (० Table 3, 0 Fig. 1 ).

Before RR, a rectocele was detected in all patients by dPF-MRI versus in only 19 (76\%) patients after surgery. Furthermore RR significantly reduced the size $(p<0.01)$ and protrusion $(p=0.03)$ of a rectocele ( $\odot$ Table 2, 0 Fig. 1 ).

These improvements in PF function and anatomy obtained from dPF-MRI led to morphologically improved defecation in all patients. Radiologically complete defecation was seen in only 2 patients before versus in 17 after $R R(p<0.01)$, indicating that the surgical treatment significantly improved the dynamic morphology of the defecation process. RR had no impact on PF descensus and led to an increase in clinically inapparent cystoceles. Nevertheless patients did not complain of a worsening of urine incontinence ( $\odot$ Table 3, $\odot$ Fig. 1,2 ). 


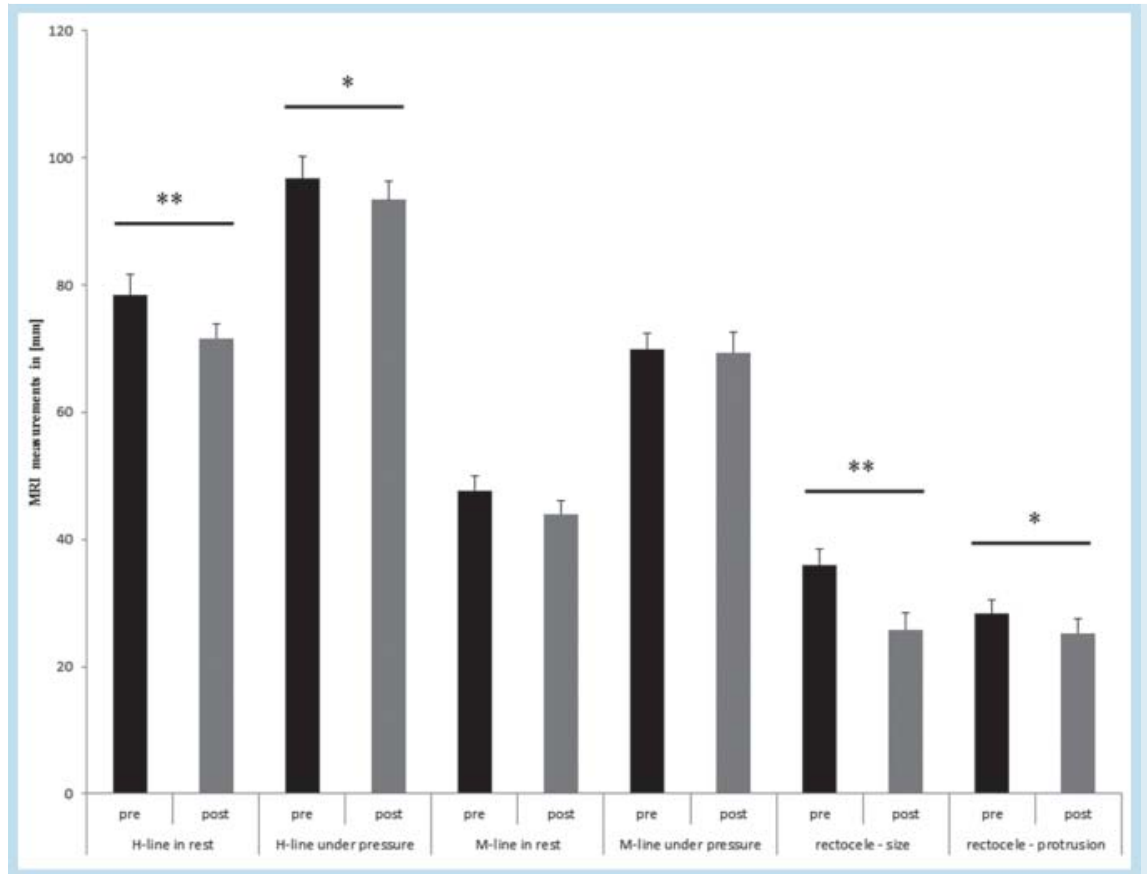

Fig. 1 dPF-MRI measurements. ${ }^{*} \mathrm{p}<0.05,{ }^{* *}$ $\mathrm{p}<0.01$.

Abb. 1 dPF-MRI-Messungen. ${ }^{*} \mathrm{p}<0,05,{ }^{* *}$ $\mathrm{p}<0,01$.

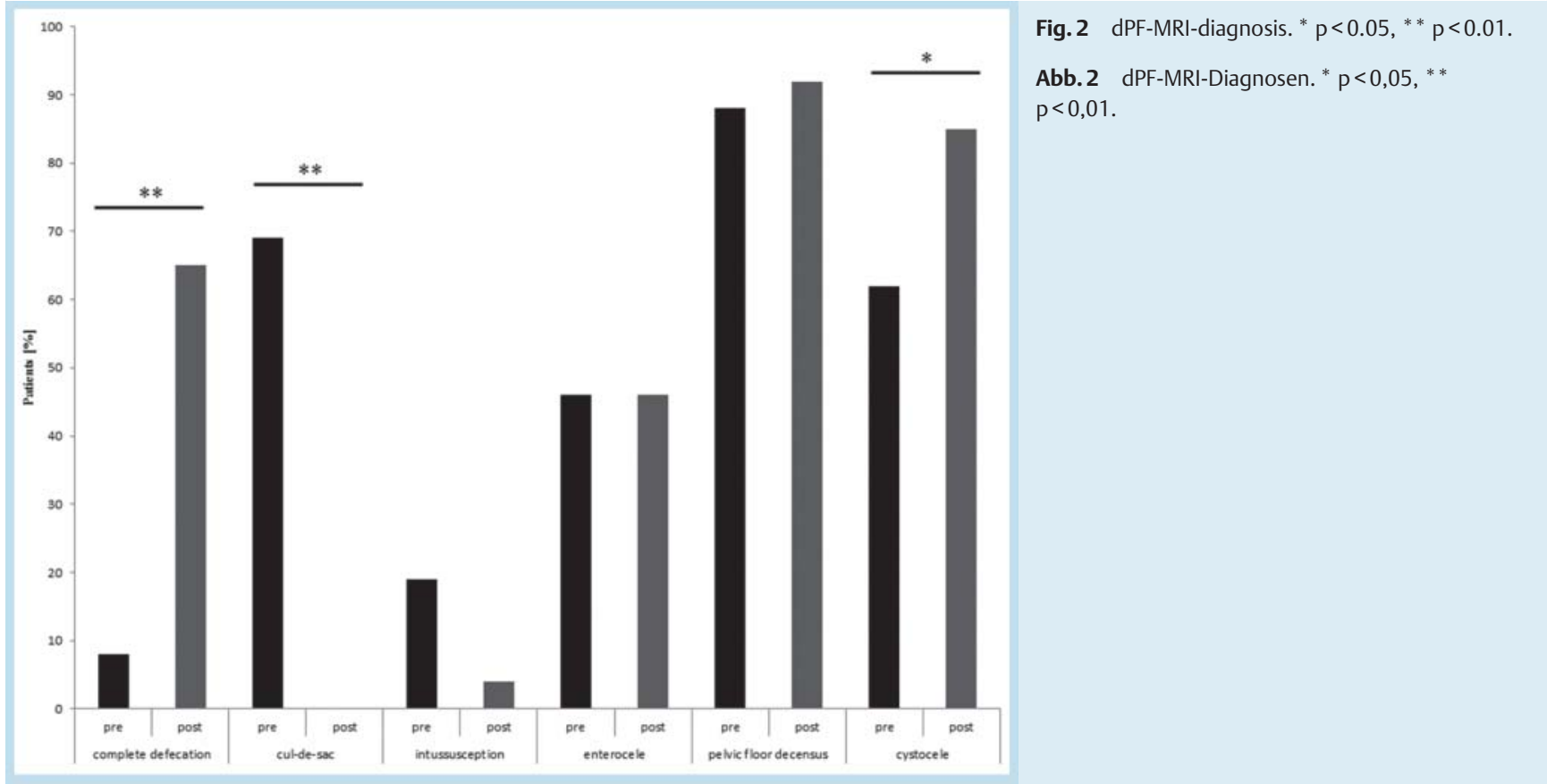

\section{Quality of life}

Patients reported significant improvements in QOL postoperatively, especially in physical functioning $(p<0.01)$, general health $(p<0.01)$, vitality $(p=0.01)$, role-emotional $(p=0.03)$ and mental health $(\mathrm{p}<0.01, \mathrm{O}$ Table 3$)$.

After 36 months of follow-up, none of the patients showed a relapse of rectal prolapse or impairment of symptoms of ODS.

\section{Discussion}

$\nabla$

PF function depends on the proper interplay of muscles, bands and nerves. This study addresses disorders of the posterior compartment (rectal prolapse, cul-de-sac and combined disease with rectocele and/or intussusception), which frequently lead to defecation failure and ODS. ODS is a common symptom of frequent organic diseases, whereby the number of unreported cases is estimated to be very high reflected by the variable prevalence rates reported in the current literature $[1,5]$. This fact is also reflected in our study by the long time from the onset of the first symp- 
toms to the first consultation with a specialized institution for colorectal diseases.

Once conservative treatment has failed in patients with ODS leading to a worsening of QOL, patients should be considered for surgery $[18,19]$.

For the surgical treatment of the underlying disease of ODS, different transabdominal and perineal approaches are described [20]. As ODS is a disease of the elderly, lower operation trauma and complications are described for perineal approaches in the treatment of rectal prolapse [21-24]. Some data suggest that perineal approaches should be preferred for older, multimorbid patients suffering from rectal prolapse due to operation risk [24]. Nevertheless recurrence as well as persistence rates of anal incontinence remain higher and functional results are poor after perineal compared with transabdominal approaches [20-22, $24-26]$. Furthermore, in a study by Laubert et al., age was not shown to be a contraindication for transabdominal RR [3].

The present study focuses on functional improvements. Thus, we did not differentiate between open and laparoscopic RR, although the study of Demirbas et al. showed an improved pain level as well as shorter postoperative hospitalization after laparoscopic compared with open RR [27] and Kariv et al. reported improvements in continence and constipation of the laparoscopically treated group compared with open surgery [28]. Furthermore, good functional results are reported for RR, even in the treatment of ODS caused by sigmoidocele and combined failures of the PF $[7,29]$.

In our study the patients profited from surgery regarding objective (clinical) und subjective features. Improvements in defecation behavior, fecal incontinence and ODS by RR had already been shown by several studies in the past [20]. The constipation rate in patients with ODS could be improved in $62-82 \%$ in previous studies, with the best results predominantly in the RR groups [30 - 32]. Bruch et al. also showed an improvement of fecal incontinence and constipation by $64 \%$ and $76 \%$, respectively [6]. In our patients the use of laxatives as well as the need for self-digitation were dramatically decreased after surgery and this is consistent with previous data $[33,34]$. In conclusion, the tension of the rectum with rectopexy restores pelvic function and thus improves fecal continence.

After the assessment of clinical and morphological changes, we investigated the impact of RR on QOL. The beneficial effects of surgical treatment led to a high increase in disease-related QOL assessed by SF-36, furthermore to a decrease of defecation-associated VAS and CCIS, reflecting good functional results after treatment. Due to a variety of different scores, a comparison of improvements in fecal incontinence with the current literature is difficult. Johnson et al. described improvements of fecal incontinence and constipation after treatment with RR for rectal prolapse, assessed by a newly designed incontinence score and the Knowles-Eccersley-Scott-Symptom questionnaire score [34]. Kneist et al. examined significant improvements in CCIS and the Cleveland Clinic constipation score after laparoscopic RR combined with intraoperative neuromapping for rectal prolapse [35] and Zittel et al. proposed good functional results after rectopexy alone with regard to CCIS, but described four patients with an impairment in chronic constipation at the same time [36].

Due to a strong heterogeneity of the trials (e.g. different inclusion and exclusion criteria), the comparison of QOL after treatment for prolapse of the rectum is also difficult. One study by Riansuwan et al. compared abdominal and perineal approaches for rectal prolapse. They showed improvements of QOL after transabdominal approaches but patients who underwent perineal surgery were significantly older and had more comorbidities, which also can result in decreased QOL [24]. Sezai et al. investigated improvements in QOL after laparoscopic RR compared with rectopexy alone [37]. As mentioned above, Demirbas et al. showed advantages after laparoscopic versus open transabdominal approaches [27]. In our study the patients were mainly treated by laparoscopic RR, which has the best evidence from the current literature regarding postoperative pain, recurrence, improvements in constipation and anal incontinence.

After the clinical and patient-related parameters of the beneficial effects of RR for ODS were addressed, changes in PF anatomy and function as well as defecation physiology after RR were investigated by dPF-MRI. dPF-MRI for the preoperative diagnosis of patients with ODS is a well-established procedure [13]. As Paetzel and colleagues published, dPF-MRI is more sensitive and accurate in diagnosing complex failure in pelvic floor function than clinical examination alone [38]. dPF-MRI thus gives therapy-relevant information about pelvic floor function [38], but to our knowledge a follow-up with dPF-MRI after RR for ODS has never been reported in the literature before. Therefore, the pubococcygeal line as well as the $\mathrm{H}$ - and $\mathrm{M}$-line were measured as previously described ( Fig. 3) $[15,16]$. Comiter et al. specified the size of the $\mathrm{H}$ - and M-line in healthy women as $5.2 \pm 1.1 \mathrm{~cm}$ and $1.9 \pm 1.2 \mathrm{~cm}$, respectively [15]. Enlargement in the $\mathrm{H}$-line indicates a widening of the hiatus of the levator ani muscle and the enlargement of the M-line indicates a PF relaxation or descensus [15]. The patient collective of the present study showed in mean a pathological widening of the hiatus musculi levator ani as well as pathological measurements of the M-line before and after surgical treatment. After surgery a significant decrease in the $\mathrm{H}$-line, but no changes in the M-line were achieved, indicating that lifting of the rectum through RR reduces the extent of the hiatus but has no influence on descensus of the PF. $100 \%$ and $96 \%$ of our patients had a detectable PF descensus in pre- and postoperative dPF-MRI $(\mathrm{p}=0.58$, 0 Table 3$)$. Because none of the patients had rectal prolapse after surgical treatment, we propose that a PF descensus, only detectable on dPF-MRI, does not correlate with the clinical manifestation of ODS symptoms and restoring of the PF anatomy must not be the target of surgical treatment to improve the symptoms and QOL of the patients. Furthermore, RR has beneficial effects on the size and protrusion of rectocele, which is a common underlying co-incidental disease of ODS. In our study all patients suffered from a rectocele preoperatively with a mean size of $36.0 \pm 2.4 \mathrm{~mm}$. This can be classified as a moderate rectocele and with appropriate symptoms this alone is an indication for surgery, whereby it is known that rectoceles as a solitary finding are markedly rare [39-41]. After treatment a rectocele could still be detected on dPF-MRI in $73 \%$ of cases, but the size and protrusion were significantly reduced, resulting in improvements in defecation and QOL. These data suggest that RR in select patients has beneficial effects on the posterior part of the PF, but restoring of anatomic reference values was not achieved by surgical treatment with RR, whereas it is not necessary to symptomatically treat the patients and improve QOL. Amongst all improvements in the posterior compartment of the PF, significantly more patients showed a cystocele in dPF-MRI studies after RR (70\% preoperatively versus $88 \%$ postoperatively, $\mathrm{p}=0.05$ ). Regarding this circumstance, patients were evaluated for subjective urinary incontinence, whereas no worsening could be detected after surgery.

We conclude that RR is the favorable surgical approach for the treatment of ODS caused by rectal prolapse, cul-de-sac syndrome 

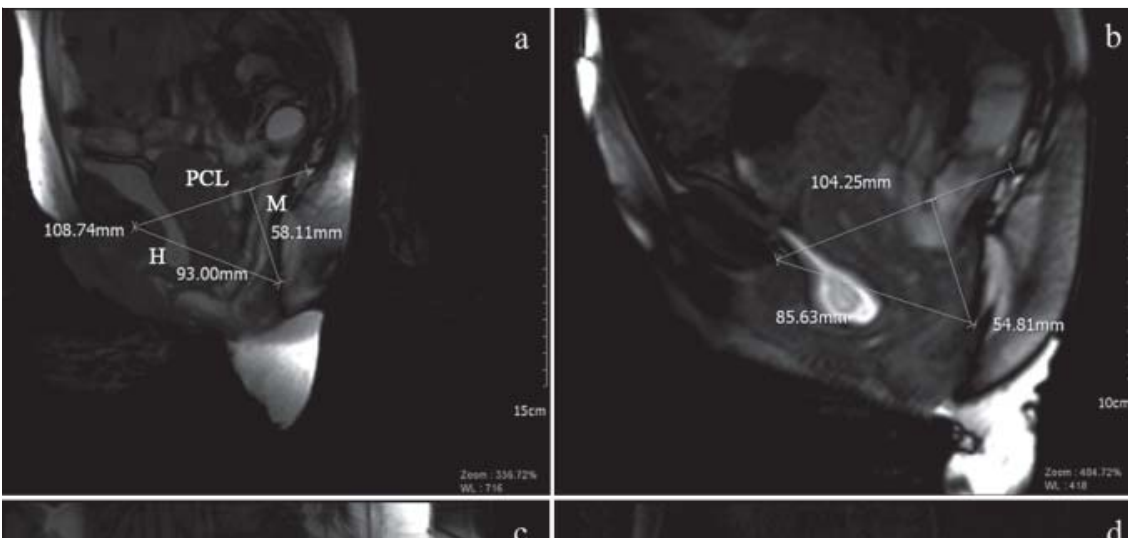

Fig. 3 dPF-MRI images. PCL-, $\mathrm{H}$ - and $\mathrm{M}$-line are depicted. $\mathbf{a}$ and $\mathbf{b}$ : pre- and postoperative dPF-MRI of a patient with cul-de-sac syndrome (before $\mathrm{H}$ : $93.0 \mathrm{~mm}, \mathrm{M}: 58.0 \mathrm{~mm}$ versus $\mathrm{H}: 85.63 \mathrm{~mm}$, M: $54.81 \mathrm{~mm}$ after RR). $\mathbf{c}$ and d: pre- and postoperative dPF-MRI imaging of a patient with prolapse of the rectum and rectocele (before $\mathrm{H}: 100.38 \mathrm{~mm}, \mathrm{M}: 72.56 \mathrm{~mm}$ versus $\mathrm{H}: 88.64 \mathrm{~mm}$, M: $59.72 \mathrm{~mm}$ after RR). In the present study RR has a significant impact on the $\mathrm{H}$ - but not on the M-line.

Abb. 3 dPF-MRI Abbildungen. PCL-, $\mathrm{H}$ - und M-Linie sind exemplarisch dargestellt.

$\mathbf{a}$ und $\mathbf{b}$ : prä- und postoperatives dPF-MRI einer Patientin mit Sigmoidozele (Cul-de-sac-Syndrom)
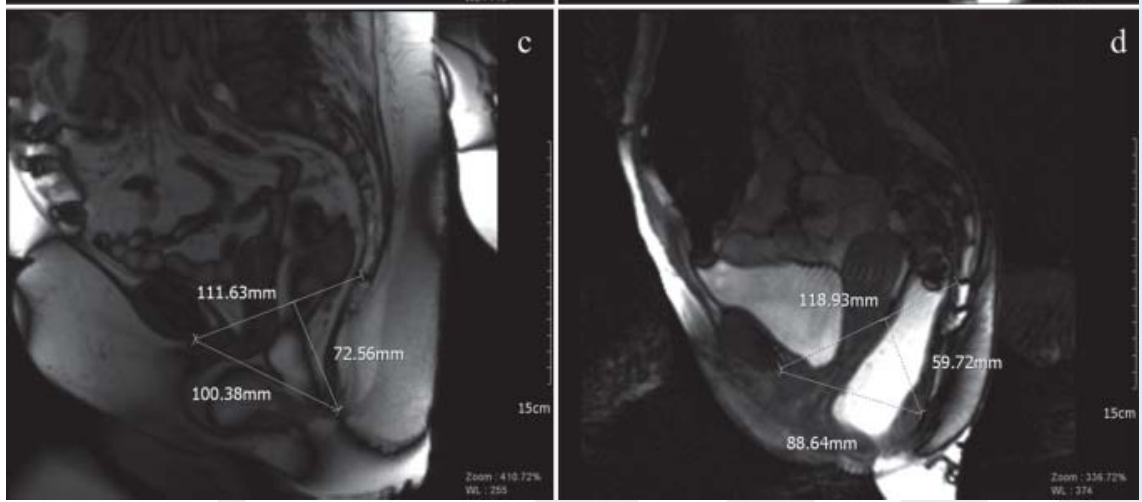
(vor RR H-Linie: 93,0 mm, M-Linie: 58,0 mm versus nach RR H-Linie: 85,63 mm, M-Linie: 59,72 mm). c und d: prä- und postoperatives dPF-MRI einer Patientin mit Rektumprolaps und Rektozele (vor RR H-Linie: $100,38 \mathrm{~mm}$, M-Linie: $72,56 \mathrm{~mm}$ versus nach RR H-Linie: 88,64 mm, M-Linie: 59,72 mm). In der vorliegenden Studie hatte die RR einen signifikanten Einfluss auf die Länge der $\mathrm{H}$-, jedoch nicht der M-Linie.

Table 3 Subjective and objective postoperative results.

Tab. 3 Postoperative Ergebnisse.

\begin{tabular}{|c|c|c|c|c|c|}
\hline \multicolumn{3}{|l|}{ parameter } & \multirow{2}{*}{$\begin{array}{c}\text { preoperative } \\
7(27 \%)\end{array}$} & \multirow{2}{*}{$\begin{array}{l}\text { postoperative } \\
13(50 \%)\end{array}$} & \multirow[t]{2}{*}{ p-value } \\
\hline \multirow{11}{*}{$\begin{array}{l}\text { changes in defecation } \\
\text { behavior }\end{array}$} & \multirow[t]{4}{*}{ fecal continence } & yes & & & \\
\hline & & $1^{\circ}$ & $7(27 \%)$ & $12(46 \%)$ & \\
\hline & & $2^{\circ}$ & $6(23 \%)$ & $1(4 \%)$ & \\
\hline & & $3^{\circ}$ & $6(23 \%)$ & none & $p<0.01$ \\
\hline & \multirow[t]{3}{*}{ consistency of stool } & fluid & $9(35 \%)$ & $8(31 \%)$ & \\
\hline & & soft and formed & $2(8 \%)$ & $11(42 \%)$ & \\
\hline & & hard & $15(58 \%)$ & $7(27 \%)$ & $p=0.66$ \\
\hline & \multicolumn{2}{|l|}{ abuse of laxatives } & $17(65 \%)$ & $7(27 \%)$ & $p=0.01$ \\
\hline & \multicolumn{2}{|l|}{ manual defecation } & $12(46 \%)$ & $4(15 \%)$ & $p=0.02$ \\
\hline & \multicolumn{2}{|c|}{ Cleveland clinic incontinence score } & $10 \pm 1.3$ & $7.3 \pm 1.0$ & $p=0.01$ \\
\hline & \multicolumn{2}{|c|}{ visual analog scale for defecation-associated pain } & $4.7 \pm 0.6$ & $1.9 \pm 0.5$ & $p<0.01$ \\
\hline \multirow[t]{12}{*}{ dPF-MRI studies } & \multirow[t]{2}{*}{ h-line (length) } & at rest & $78.5 \pm 3.2 \mathrm{~mm}$ & $71.6 \pm 2.2 \mathrm{~mm}$ & $p<0.01$ \\
\hline & & under abdominal pressure & $96.8 \pm 3.4 \mathrm{~mm}$ & $93.4 \pm 3.0 \mathrm{~mm}$ & $p=0.04$ \\
\hline & \multirow[t]{2}{*}{ m-line (length) } & at rest & $47.7 \pm 2.2 \mathrm{~mm}$ & $44.0 \pm 2.0 \mathrm{~mm}$ & $p=0.06$ \\
\hline & & under abdominal pressure & $69.8 \pm 2.6 \mathrm{~mm}$ & $69.4 \pm 3.1 \mathrm{~mm}$ & $p=0.62$ \\
\hline & \multirow{3}{*}{ assessment of the rectocele } & presence of a rectocele & $23(100 \%)$ & $19(76 \%)$ & \\
\hline & & size of the rectocele & $36.0 \pm 2.4 \mathrm{~mm}$ & $25.8 \pm 2.6 \mathrm{~mm}$ & $p<0.01$ \\
\hline & & $\begin{array}{l}\text { protrusion of the } \\
\text { rectocele }\end{array}$ & $28.4 \pm 2.1 \mathrm{~mm}$ & $25.2 \pm 2.4 \mathrm{~mm}$ & $p=0.03$ \\
\hline & \multicolumn{2}{|l|}{ cul-de-sac syndrome } & $18(78 \%)$ & $0(0 \%)$ & $p<0.01$ \\
\hline & \multicolumn{2}{|l|}{ intussusception } & $5(22 \%)$ & $1(4 \%)$ & $P=0.06$ \\
\hline & \multicolumn{2}{|l|}{ complete defecation } & $2(8 \%)$ & $17(68 \%)$ & $p<0.01$ \\
\hline & \multicolumn{2}{|l|}{ cystocele } & $16(70 \%)$ & $22(88 \%)$ & $p=0.05$ \\
\hline & \multicolumn{2}{|l|}{ pelvic floor descensus } & $23(100 \%)$ & $24(96 \%)$ & $p=0.58$ \\
\hline \multirow[t]{9}{*}{ quality of life } & \multicolumn{2}{|l|}{ overall changes of health } & $39.13 \pm 5.84$ & $73.0 \pm 5.19$ & $p<0.01$ \\
\hline & \multirow[t]{8}{*}{ physical health } & physical functioning & $65.38 \pm 5.53$ & $80.21 \pm 5.22$ & $p<0.01$ \\
\hline & & physical role functioning & $40.63 \pm 7.79$ & $69.74 \pm 9.28$ & $p=0.19$ \\
\hline & & bodily pain & $48.13 \pm 5.77$ & $67.89 \pm 5.86$ & $p=0.16$ \\
\hline & & general health & $39.32 \pm 3.85$ & $59.96 \pm 4.32$ & $p<0.01$ \\
\hline & & vitality & $34.4 \pm 3.9$ & $53.91 \pm 4.43$ & $p=0.01$ \\
\hline & & social functioning & $51.04 \pm 6.06$ & $62.5 \pm 5.98$ & $p=0.14$ \\
\hline & & role-emotional & $44.44 \pm 8.19$ & $73.68 \pm 9.39$ & $p=0.03$ \\
\hline & & mental health & $47.04 \pm 4.03$ & $63.48 \pm 4.19$ & $p<0.01$ \\
\hline
\end{tabular}


and combined disease with intussusception and/or rectocele in select patients. A return to a normal PF anatomy in postoperative dPF-MRI studies was not required to improve PF function and patient QOL.

\section{Clinical Relevance}

- This study gives new insights into changes in pelvic floor anatomy and function after resection rectopexy for obstructed defecation syndrome.

- Resection rectopexy is a routinely used surgical approach for underlying diseases of obstructed defecation syndrome, whereas the morphological impact on the pelvic floor had never been described before.

- Resection rectopexy has the power to symptomatically treat selected patients with obstructed defecation syndrome. This study helps with the understanding of the correlations between changes of the pelvic floor and quality of life of patients after surgery.

\section{References}

1 Suares NC, Ford AC. Prevalence of, and risk factors for, chronic idiopathic constipation in the community: systematic review and metaanalysis. Am J Gastroenterol 2011; 106: 1582 - 1591; quiz 1581, 1592

2 D'Hoore A, Penninckx F. Obstructed defecation. Colorectal Dis 2003; 5: $280-287$

3 Laubert T, Bader FG, Kleemann M et al. Outcome analysis of elderly patients undergoing laparoscopic resection rectopexy for rectal prolapse. Int J Colorectal Dis 2012; 27: 789-795

$4 \mathrm{Kim}$ M, Isbert C. Anorectal functional diagnostics. Therapy algorithm for obstruction and incontinence. Chirurg 2013; 84: 7-14

5 Andromanakos $N$, Skandalakis $P$, Troupis T et al. Constipation of anorectal outlet obstruction: pathophysiology, evaluation and management. J Gastroenterol Hepatol 2006; 21: 638-646

6 Bruch HP, Herold A, Schiedeck T et al. Laparoscopic surgery for rectal prolapse and outlet obstruction. Dis Colon Rectum 1999; 42: 11891194; discussion 1194-1185

7 Laubert T, Kleemann M, Roblick UJ et al. Obstructive defecation syndrome: 19 years of experience with laparoscopic resection rectopexy. Tech Coloproctol 2013; 17: 307-314

8 Keighley MR, Fielding JW, Alexander-Williams J. Results of Marlex mesh abdominal rectopexy for rectal prolapse in 100 consecutive patients. Br J Surg 1983; 70: 229-232

9 Luukkonen P, Mikkonen U, Jarvinen H. Abdominal rectopexy with sigmoidectomy vs. rectopexy alone for rectal prolapse: a prospective, randomized study. Int J Colorectal Dis 1992; 7: 219-222

10 Aitola PT, Hiltunen KM, Matikainen MJ. Functional results of operative treatment of rectal prolapse over an 11-year period: emphasis on transabdominal approach. Dis Colon Rectum 1999; 42: 655-660

11 McKee RF, Lauder JC, Poon FW et al. A prospective randomized study of abdominal rectopexy with and without sigmoidectomy in rectal prolapse. Surg Gynecol Obstet 1992; 174: 145-148

12 Madoff RD, Williams JG, Wong WD et al. Long-term functional results of colon resection and rectopexy for overt rectal prolapse. Am J Gastroenterol 1992; 87: 101 - 104

13 Bolog N, Weishaupt D. Dynamic MR imaging of outlet obstruction. Rom J Gastroenterol 2005; 14: 293-302

14 Jorge JM, Wexner SD. Etiology and management of fecal incontinence. Dis Colon Rectum 1993; 36: 77-97

15 Comiter CV, Vasavada SP, Barbaric ZL et al. Grading pelvic prolapse and pelvic floor relaxation using dynamic magnetic resonance imaging. Urology 1999; 54: 454-457

16 Yang A, Mostwin JL, Rosenshein NB et al. Pelvic floor descent in women: dynamic evaluation with fast MR imaging and cinematic display. Radiology 1991; 179: 25 - 33

17 Schwandner T, Hecker A, Hirschburger $M$ et al. Does the STARR procedure change the pelvic floor: a preoperative and postoperative study with dynamic pelvic floor MRI. Dis Colon Rectum 2011; 54: 412-417
18 Lehur PA, Stuto A, Fantoli $M$ et al. Outcomes of stapled transanal rectal resection vs. biofeedback for the treatment of outlet obstruction associated with rectal intussusception and rectocele: a multicenter, randomized, controlled trial. Dis Colon Rectum 2008; 51: 1611-1618

19 Formijne Jonkers HA, Draaisma WA, Wexner SD et al. Evaluation and surgical treatment of rectal prolapse: an international survey. Colorectal Dis 2013; 15: $115-119$

20 Laubert T, Kleemann M, Schorcht A et al. Laparoscopic resection rectopexy for rectal prolapse: a single-center study during 16 years. Surg Endosc 2010; 24: $2401-2406$

21 Williams JG, Rothenberger DA, Madoff RD et al. Treatment of rectal prolapse in the elderly by perineal rectosigmoidectomy. Dis Colon Rectum 1992; 35: 830-834

22 Kimmins $M H$, Evetts BK, Isler J et al. The Altemeier repair: outpatient treatment of rectal prolapse. Dis Colon Rectum 2001; 44: 565-570

23 Oliver GC, Vachon D, Eisenstat TE et al. Delorme's procedure for complete rectal prolapse in severely debilitated patients. An analysis of 41 cases. Dis Colon Rectum 1994; 37: 461 - 467

24 Riansuwan W, Hull TL, Bast J et al. Comparison of perineal operations with abdominal operations for full-thickness rectal prolapse. World J Surg 2010; 34: 1116-1122

25 Agachan F, Reissman P, Pfeifer J et al. Comparison of three perineal procedures for the treatment of rectal prolapse. South Med J 1997; 90: 925-932

26 Kim DS, Tsang CB, Wong WD et al. Complete rectal prolapse: evolution of management and results. Dis Colon Rectum 1999; 42: 460-466; discussion 466-469

27 Demirbas S, Akin ML, Kalemoglu M et al. Comparison of laparoscopic and open surgery for total rectal prolapse. Surg Today 2005; 35: $446-452$

28 Kariv Y, Delaney CP, Casillas $S$ et al. Long-term outcome after laparoscopic and open surgery for rectal prolapse: a case-control study Surg Endosc 2006; 20: 35-42

29 Tsiaoussis J, Chrysos E, Athanasakis E et al. Rectoanal intussusception: presentation of the disorder and late results of resection rectopexy. Dis Colon Rectum 2005; 48: 838 -844

30 Benoist S, Taffinder N, Gould S et al. Functional results two years after laparoscopic rectopexy. Am J Surg 2001; 182: 168-173

31 Stevenson AR, Stitz RW, Lumley JW. Laparoscopic-assisted resectionrectopexy for rectal prolapse: early and medium follow-up. Dis Colon Rectum 1998; 41: 46-54

32 Ashari LH, Lumley JW, Stevenson AR et al. Laparoscopically-assisted resection rectopexy for rectal prolapse: ten years' experience. Dis Colon Rectum 2005; 48: 982 - 987

33 Johnson E, Carlsen E, Mjaland O et al. Resection rectopexy for internal rectal intussusception reduces constipation and incomplete evacuation of stool. Eur J Surg Suppl 2003: 51 -56

34 Johnson E, Stangeland A, Johannessen $\mathrm{HO}$ et al. Resection rectopexy for external rectal prolapse reduces constipation and anal incontinence. Scand J Surg 2007; 96: 56-61

35 Kneist $W$, Kauff DW, Naumann $G$ et al. Resection rectopexy-laparoscopic neuromapping reveals neurogenic pathways to the lower segment of the rectum: preliminary results. Langenbecks Arch Surg 2013: $398: 565-570$

36 Zittel TT, Manncke K, Haug S et al. Functional results after laparoscopic rectopexy for rectal prolapse. J Gastrointest Surg 2000; 4: 632 -641

37 Sezai $D$, Demirbas $S$, Akin $L$ et al. The impact of laparoscopic resection rectopexy in patients with total rectal prolapse. Mil Med 2005; 170: $743-747$

38 Paetzel C, Strotzer M, Furst A et al. Dynamic MR defecography for diagnosis of combined functional disorders of the pelvic floor in proctology. Rofo 2001; 173: 410-415

39 Roos JE, Weishaupt D, Wildermuth $S$ et al. Experience of 4 years with open MR defecography: pictorial review of anorectal anatomy and disease. Radiographics 2002; 22: 817-832

40 Siproudhis L, Dautreme S, Ropert A et al. Dyschezia and rectocele-a marriage of convenience? Physiologic evaluation of the rectocele in a group of 52 women complaining of difficulty in evacuation. Dis Colon Rectum 1993; 36: 1030 - 1036

41 Maglinte DD, Kelvin FM, Fitzgerald K et al. Association of compartment defects in pelvic floor dysfunction. Am J Roentgenol 1999; 172: 439 444 